\title{
On the use of certified reference materials for assuring the quality of results for the determination of mercury in environmental samples
}

\author{
Ewa Bulska $^{1}$ (D) Agnieszka Krata ${ }^{1}$ Mateusz Kalabun ${ }^{1,2} \cdot$ Marcin Wojciechowski $^{1}$
}

Received: 17 February 2016 / Accepted: 14 July 2016 / Published online: 15 August 2016

(C) The Author(s) 2016. This article is published with open access at Springerlink.com

\begin{abstract}
This work focused on the development and validation of methodologies for the accurate determination of mercury in environmental samples and its further application for the preparation and certification of new reference materials (RMs). Two certified RMs ERM-CC580 (inorganic matrix) and ERMCE464 (organic matrix) were used for the evaluation of digestion conditions assuring the quantitative recovery of mercury. These conditions were then used for the digestion of new candidates for the environmental RMs: bottom sediment (M_2 BotSed), herring tissue (M_3 HerTis), cormorant tissue (M_4 CormTis), and codfish muscle (M_5 CodTis). Cold vapor atomic absorption spectrometry (CV AAS) and inductively coupled plasma mass spectrometry (ICP MS) were used for the measurement of mercury concentration in all RMs. In order to validate and assure the accuracy of results, isotope dilution mass spectrometry (IDMS) was applied as a primary method of measurement, assuring the traceability of obtained values to the SI units: the mole, the kilogram, and the second. Results obtained by IDMS using $n\left({ }^{200} \mathrm{Hg}\right) / n\left({ }^{202} \mathrm{Hg}\right)$ ratio, with estimated combined uncertainty, were as follows: $(916 \pm 41) /[4.5 \%]$ ng g ${ }^{-1}$ (M_2 BotSed), $(236 \pm 14) /[5.9 \%] \mathrm{ng} \mathrm{g}^{-1}$ (M_3 HerTis), $(2252 \pm 54) /[2.4 \%] \mathrm{ng} \mathrm{g}^{-1}$ (M_4 CormTis), and $(303 \pm 15) /[4.9 \%] \mathrm{ng} \mathrm{g}^{-1}$ (M_CodTis), respectively. Different types of detection techniques and quantification
\end{abstract}

Responsible editor: Philippe Garrigues

Ewa Bulska

ebulska@chem.uw.edu.pl

1 Faculty of Chemistry, Biological and Chemical Research Centre, University of Warsaw, Żwirki i Wigury 101, 02-089 Warsaw, Poland

2 Inter-Faculty Interdisciplinary Doctoral Studies in Natural Sciences and Mathematics, University of Warsaw, Żwirki i Wigury 93, 02-089 Warsaw, Poland (external calibration, standard addition, isotope dilution) were applied in order to improve the quality of the analytical results. The good agreement (within less than $2.5 \%$ ) between obtained results and those derived from the Inter-laboratory Comparison, executed by the Institute of Nuclear Chemistry and Technology (Warsaw, Poland) on the same sample matrices, further validated the analytical procedures developed in this study, as well as the concentration of mercury in all four new RMs. Although the developed protocol enabling the metrological certification of the reference value was exemplified by the determination of mercury in environmental samples, it could be considered as valid for any certification procedure required whenever new certified RMs are introduced.

Keywords Quality of results · Environmental reference material $\cdot$ Mercury determination $\cdot$ Isotope dilution $\cdot$ Mass spectrometry

\section{Introduction}

The quality of results is an important issue in a whole range of scientific disciplines, in which chemical measurements are necessary. It has been recognized by those interested in environmentally related investigations that the quality of analytical results should be transparent and confident. Therefore, it is important to deliver accurate results and to be able to show their traceability (Bulska 2009).

Mercury was found to be one of the most toxic elements (Leermakers et al. 2005; Lubick 2009), causing several symptoms related to polyneuropathy mercurialis, neuroasthemia, tremor mercurialis, and other (Harada et al. 1999). Therefore, mercury pollution is an important issue that demands an ongoing development of analytical procedures to ensure its reliable determination. Certified reference materials 
(CRMs) are recognized to be an essential tool in assuring the accuracy and establishing the traceability of the results of measurements (Quevauviller et al. 1996). Thus, there is a need to introduce new CRMs in order to fulfill the demand of the environmentally oriented studies. So far, several analytical techniques were applied for the determination of mercury in various matrices and at various levels of concentration. The cold vapor atomic absorption spectrometry (CV AAS) is recognized to be one of the most widely used techniques for the determination of mercury. As the vapor of mercury is generated, it separates from the matrix, with a very high efficiency of analyte introduction. These features are crucial, when the concentration of mercury in the sample is low and the matrix is complex. Advantages of CV AAS resulted in its frequent use for the determination of mercury in biological samples (Shah et al. 2010; Torres et al. 2009), hair (Bruhn et al. 1994), slurries (Torres et al. 2009), water (Krata et al. 2002), and food packaging (Perring et al. 2001). Cold vapor generation was also combined with atomic fluorescence spectrometry (CV AFS) (da Silva et al. 2010; Li and Wang 2007) or inductively coupled plasma mass spectrometry (ICP MS) (Kenduzler et al. 2012; Knight et al. 1999).

The ICP MS has several advantages, such as high sensitivity and precision, excellent detection limits (below $0.01 \mu \mathrm{g} \mathrm{L}^{-1}$ ), selectivity, and possibility, to determine various isotopes of the element of interest. It was used for the determination of total mercury concentration in blood samples (McShane et al. 2008), marine organisms (Arslan et al. 2000; Falter and Ilgen 1997), food (Shuqin et al. 1999), sediments (Arslan et al. 2000; Falter and Ilgen 1997), water (Cattani et al. 2008; Soares dos Santos et al. 2009), and drugs (Wu et al. 2002). It should be mentioned, however, that the possible loss of mercury, due to its volatility during digestion or its ability for adsorption on the tubes' walls of ICP MS sample introduction system, has to be considered. The last could be responsible for the memory effect; thus, several reagents (e.g., L-cysteine, thiourea, or gold chloride) were used to minimize it (Chen et al. 2000; Harrington et al. 2004; Li et al. 2006).

Isotope dilution mass spectrometry (IDMS) was used as a primary method of measurement, for the accurate determination of total mercury concentration (Heumann 2004; Quinn 1997; Taylor et al. 2001; Vogl and Pritzkow 2010). According to the definition of the Consultative Committee for Amount of Substance (Comite' Consultatif pour la Quantite' de Matie're, CCQM), "a primary method is a method having the highest metrological qualities, whose operation can be completely described and understood, for which a complete uncertainty statement can be written down in term of SI units". The IDMS approach is based on mathematical equation, which is well described. It consists of tabulated quantities, such as atomic weights and isotope abundances, as well as masses of sample and spike solution and, last but not least, isotopic ratios corrected for the mass discrimination effects (Vogl and Pritzkow 2010). Isotopic ratio in the mixture of sample and isotopically enriched standard is the only quantity, which is calculated from the ICP MS measurements of selected isotopes. Thereby, it is possible to calculate the concentration of an analyte with high accuracy and precision. Moreover, no quantitative recovery of analyte is required to obtain unbiased values after isotopic equilibrium is achieved. Although results obtained using IDMS approach provide traceability with SI unit system like the mole, the kilogram, and the second (Quinn 1997), it should be stressed that isotope dilution method is rarely used for routine measurements. The main field of its application is the certification of reference materials and enriched standards, where high accuracy, low uncertainty of measurement, and high quality of analytical results are the most important factors (Heumann 2004; Quinn 1997; Vogl and Pritzkow 2010).

Several approaches to environmental sample preparation before final measurements can be found in the literature; the microwave assisted digestion in closed vessels is commonly used for this purpose (da Silva et al. 2010; Falciani et al. 2000; Hoenig 2001). Nitric acid (V) alone is sufficient for digestion of organic reach matter; however, addition of hydrogen peroxide or hydrochloric acid can improve the performance and effectiveness of digestion (Aurelio and Arruda 2007; da Silva et al. 2010; Hoenig 2001; Knight et al. 1999). Soil and sediment matrices containing aluminosilicate require the addition of hydrofluoric acid or $\mathrm{HCl}$ (Arslan et al. 2000; Falciani et al. 2000). The use of aqua regia for the digestion of soils or sediments was also reported (Hoenig 2001; Smith 1993). In order to evaluate whether the selected digestion procedure does not cause the loss of some volatile elements, e.g., mercury, CRMs need to undergo the entire analytical procedure.

The aim of this work was to evaluate analytical procedures and measurement methods for the determination of mercury concentration in candidates for certified environmental reference materials obtained with metrological high quality. Two kinds of environmental materials (with inorganic and organic matrix) were used, and several digestion processes were assessed in order to receive quantitative recovery of mercury. Then, two analytical techniques such as ICP MS and CV AAS under different calibration strategies (external calibration, standard addition) were applied and compared. After that, IDMS measurements were performed. All the experiments were carried out towards certification of mercury concentration in candidates for CRMs.

The developed entire strategy for the metrological certification of the reference values could be however applied not only for the particular case described in this work. This 
protocol, which was proved to give metrological quality of the results, could be applied in any certification processes.

\section{Materials and methods}

Trace analysis grade reagents nitric acid (Merck, Germany), hydrochloric and sulfuric acids (J.T.Baker, USA), hydrofluoric acid (Fluka, Germany), perchloric and tetrafluoroboric acids (Sigma-Aldrich, USA), as well as hydrogen peroxide (Fluka, Germany) were used for digestion of the samples. Sodium tetrahydridoborate (Sigma-Aldrich, USA) was used as reducing agent for CV AAS.

Two reference materials were used for the optimization of sample digestion: ERM-CC580 (Institute for Reference Materials and Measurements, IRMM, Belgium) estuarine sediment with the certified total mercury content of (132 \pm 3$)$ $\mu \mathrm{g} \mathrm{g}^{-1}$ and ERM-CE464 tuna fish (IRMM, Belgium) with the certified total mercury content of $(5.24 \pm 0.10) \mu \mathrm{g} \mathrm{g}^{-1}$.

Isotopically enriched standard ERM-AE640 (IRMM, Belgium) enriched in $95.7 \%$ of ${ }^{202} \mathrm{Hg}$ with mercury concentration of $(1.506 \pm 0.011) \cdot 10^{-5} \mathrm{~mol} \mathrm{~kg}^{-1}$ was used for spiking the samples. ERM-AE639 Isotopic Reference Material (IRMM, Belgium) with mercury concentration $(3.971 \pm 0.015) \cdot 10^{-5} \mathrm{~mol} \mathrm{~kg}^{-1}$ was used for the correction of mass discrimination effects.

The $1641 \mathrm{~d}$ mercury standard solution with concentration of $(1.557 \pm 0.020) \mathrm{mg} \mathrm{kg}^{-1}$ (NIST, USA) was used for calibration of ICP MS and CV AAS instruments, as well as for the standard addition ICP MS measurements. Standard solution of $1641 \mathrm{~d}$ was diluted gravimetrically prior to use.

Rhodium standard solution and gold standard solution (Merck, Germany) each with concentration $1 \mathrm{~g} \mathrm{~L}^{-1}$ during measurements by calibration curve ICP MS were used.

The working standard solutions and blend solutions were prepared gravimetrically by appropriate dilution of the stock standard solutions using an analytical balance (Mettler Toledo, Switzerland).

Four candidates for CRMs with different matrix compositions identified as MODAS 2, MODAS 3, MODAS 4, and MODAS 5 (Institute of Nuclear Chemistry and Technology, IChTJ, Poland) (Table 1) were examined for the mercury concentration.

\section{Instrumentation}

NexION 300D (PerkinElmer, USA) was used for the ICP MS measurements. The optimized working conditions used for mercury determination are listed in Table 2.

In case of IDMS approach, the signal intensities per replicate were corrected for dead time, instrumental background, and possible interferences prior to calculating an average isotopic ratio and its relative standard deviation. The dead time value and its associated standard uncertainty for every element were determined according to correction methods described by Nelms et al. (2001). The ratios $n\left({ }^{200} \mathrm{Hg}\right) / n\left({ }^{202} \mathrm{Hg}\right)$ and $n\left({ }^{201} \mathrm{Hg}\right) / n\left({ }^{202} \mathrm{Hg}\right)$ were selected for the mercury concentrations determination as all isotopes are free of significant spectral interferences. The mass discrimination effects were evaluated by measuring the ratio of $n\left({ }^{200} \mathrm{Hg}\right) / n\left({ }^{202} \mathrm{Hg}\right)$ and $n\left({ }^{201} \mathrm{Hg}\right) / n\left({ }^{202} \mathrm{Hg}\right)$ in the diluted ERM-AE639 standard solution containing around $5 \mathrm{ng} \mathrm{g}^{-1}$ of mercury and calculating the $K^{200 / 202}$ and $K^{201 / 202}$ factors from the ratio of the International Union of Pure and Applied Chemistry (IUPAC) data (Berglund and Wieser 2011) and the measured values. The mass discrimination correction was straightforward and resulted from the multiplication of the every measured blend ratio by the proper $K^{200 / 202}$ factor or and $K^{201 / 202}$ factor measured shortly after the blend. The analysis was performed according to the bracketing approach with an additional K-factor measurement at the end.

The procedural blanks, prepared in the same way as the samples or blend solutions, were determined by external calibration with three different concentrations of mercury, prepared by dilution of the respective standards.

FIMS 100 (PerkinElmer, Germany) atomic absorption spectrometer with a flow-injection unit was used for the determination of mercury. Samples were introduced by means of a $200-\mu \mathrm{L}$ loop and reduction was performed by freshly prepared $\mathrm{NaBH}_{4}$ solution. Measurements were carried out in the peak-height mode. The optimized working conditions of cold vapor atomic absorption spectrometry (CV AAS) are presented in Table 3 (Krata et al. 2003).

A microwave closed digestion unit (Ultrawave, Milestone, USA) was used for digestion of samples. Two programs were used for the optimization of digestion protocol of investigated samples (Table 4).

The main differences between digestion programs were as follows: in program I, ramp time was $15 \mathrm{~min}$ and the
Table 1 List of candidates for certified reference materials

\begin{tabular}{lll}
\hline No. & ID & Matrix \\
\hline 1 & MODAS 2: M_2 BotSed & Bottom sediment (from Vistula River near Włocławek city, Poland) \\
2 & MODAS 3: M_3 HerTis & Herring tissue (Clupea harengus) (from the North Sea) \\
3 & MODAS 4: M_4 CormTis & Cormorant tissue (Phalacrocorax carbo) (from Czech Republic) \\
4 & MODAS 5: M_5 CodTis & Codfish tissue (Gadus morhua) (from Baltic Sea) \\
\hline
\end{tabular}


Table 2 ICP MS optimized working parameters

\begin{tabular}{cc}
\hline Parameter & Description \\
\hline Spray chamber & Cyclonic, Scott type \\
Nebulizer & Quartz coaxial, type Meinhard \\
Plasma torch & Quartz \\
Sampler cone & Nickel \\
Skimmer cone & Nickel \\
Hyper skimmer cone & Aluminum \\
Plasma gas flow & $16 \mathrm{~L} \mathrm{~min}^{-1}$ \\
Nebulizing gas flow & $1 \mathrm{~L} \mathrm{~min}{ }^{-1}$ \\
RF power & $1600 \mathrm{~W}$ \\
Analog detector voltage & $-1800 \mathrm{~V}$ \\
Pulse detector voltage & $950 \mathrm{~V}$ \\
Lens voltage & $-9 \mathrm{~V}$ \\
Dead time of detector & $25 \mathrm{~ns}^{-1}$ \\
Sample flow & $1 \mathrm{~mL} \mathrm{~min}^{-1}$ \\
Number of sweeps & 5 \\
Number of repeats & 6 \\
Integration time & $150 \mathrm{~ms}^{202} \mathrm{Hg}$ \\
Monitored isotopes & ${ }^{200} \mathrm{Hg},{ }^{201} \mathrm{Hg}^{20}$ \\
\hline
\end{tabular}

maximum temperature was $240{ }^{\circ} \mathrm{C}$; in the case of program II, ramp time was extended to $25 \mathrm{~min}$ and maximum temperature was reduced to $170{ }^{\circ} \mathrm{C}$.

\section{Results and discussion}

\section{Determination of the moisture content}

A correction for the moisture content was applied to all results. For the certified reference materials ERM-CC580 and ERMCE464, the correction to dry mass was made by taking a separate portion of $100 \mathrm{mg}$ and dried in an oven at $105{ }^{\circ} \mathrm{C}$ for $4 \mathrm{~h}$, as recommended by the producer (IRMM). Samples of M_2 were dried at $105^{\circ} \mathrm{C}$ for $24 \mathrm{~h}$; all others samples were dried at $85^{\circ} \mathrm{C}$ for $48 \mathrm{~h}$, as recommended by the producer (IChTJ). Correction for dry mass was obtained from separate portions of the material mass of $0.2-0.4 \mathrm{~g}$ (ten subsamples from five bottles). The weighing and repeated drying were

Table 3 CV AAS optimized working parameters

\begin{tabular}{cl}
\hline Parameter & Description \\
\hline \multicolumn{1}{c}{ Carrier gas } & Argon \\
Carrier gas flow & $75 \mathrm{~mL} \mathrm{~min}^{-1}$ \\
Reduction agent & $\mathrm{NaBH}_{4}, 0.025 \% \mathrm{w} / \mathrm{v}$ \\
Rinse solution & $\mathrm{HCl}, 3 \% \mathrm{w} / \mathrm{w}$ \\
Measurement mode & Peak area (integrated absorbance) \\
\hline
\end{tabular}

Table 4 Programs used for the digestion of examined samples

\begin{tabular}{lcc}
\hline Parameter & Program I & Program II \\
\hline Ramp time, min & 15 & 25 \\
Hold time, min & 15 & 15 \\
$T_{\min },{ }^{\circ} \mathrm{C}$ & 20 & 20 \\
$T_{\max },{ }^{\circ} \mathrm{C}$ & 240 & 170 \\
Pressure, bar & 140 & 110 \\
\hline
\end{tabular}

performed until constant mass was attained (0.0002 $\mathrm{g}$ difference between two successive weight measurements). The average moisture content was calculated and used for the mercury content correction of each sample. In case of ERMCC580 and ERM-CE464, the moisture content was as follows: 5.1 and $7.5 \%$, respectively. For M_2, M_3, M_4, and M_5 the moisture content was found to be $4.3 \%, 6.9 \%, 5.1$ $\%$, and $5.6 \%$, respectively. According to producers' instruction for the use of CRMs, the correction to dry mass should be made as the certified values are based on dry mass.

\section{Optimization of sample digestion conditions}

The first part of this study was focused on the evaluation of the digestion procedures in order to obtain maximum recovery of mercury. CRMs of inorganic and organic matrix estuarine sediment (ERM-CC580) and tuna fish tissue (ERM-CE464) were used for this purpose. About $0.4 \mathrm{~g}$ of each material was weighted in the digestion vessel. After all reagents were added, the Teflon vessels were closed and put into the digestion unit. After careful optimization, two programs were used: program I and II, which were applied to the inorganic or organic matrix, respectively. Six different mixtures of acids were examined for the digestion of the ERM-CC580 (an example of inorganic matrix). The ICP MS calibration curve with Rh as internal standard was used for the determination of mercury in digested solutions. Composition of digestion mixtures and results calculated for various isotopes of mercury are presented in Table 5.

Almost all obtained results (except when mixture of $3 \mathrm{~mL}$ $\mathrm{HF}+2 \mathrm{~mL} \mathrm{H}_{2} \mathrm{SO}_{4}+1 \mathrm{~mL} \mathrm{H}_{2} \mathrm{O}_{2}$ was used; -line 3 in the Table 5) were consistent with certified value for the total mercury concentration within its uncertainty in the ERM-CC580. Finally, the mixture of $1 \mathrm{~mL} \mathrm{HF}+1 \mathrm{~mL} \mathrm{HCl}+3 \mathrm{~mL} \mathrm{HNO}_{3}$ with the highest accuracy and lowest uncertainty was selected for digestion of M_2 sediment sample.

For the digestion of the ERM-CE464 (an example of biological matrix), five different mixtures of acids were examined. The digestion program II was used. The ICP MS calibration curve with $\mathrm{Rh}$ as internal standard was used for the determination of mercury in digested solutions. Composition of digestion mixtures and obtained results are presented in Table 6. 
Table 5 Mercury concentration in ERM-CC580 certified reference material. Results expressed in microgram per gram (the extended uncertainty $(k=2)$ in $\left.\mu \mathrm{g} \mathrm{g}^{-1} / \%\right)$. Digestion conditions as in program I

\begin{tabular}{|c|c|c|c|c|}
\hline No. & $\mathrm{C}_{\mathrm{Hg}}\left({ }^{200} \mathrm{Hg} \pm \mathrm{Uc}\right) / \mathrm{Uc}[\%]$ & $\mathrm{C}_{\mathrm{Hg}}\left({ }^{201} \mathrm{Hg} \pm \mathrm{Uc}\right) / \mathrm{Uc}[\%]$ & $\mathrm{C}_{\mathrm{Hg}}\left({ }^{202} \mathrm{Hg} \pm \mathrm{Uc}\right) / \mathrm{Uc}[\%]$ & Composition of digestion mixture \\
\hline 1 & $(133 \pm 2) /[1.5]$ & $(133 \pm 2) /[1.5]$ & $(132 \pm 2) /[1.5]$ & $1 \mathrm{~mL} \mathrm{HF}+1 \mathrm{~mL} \mathrm{HCl}+3 \mathrm{~mL} \mathrm{HNO}_{3}$ \\
\hline 2 & $(130 \pm 7) /[5.4]$ & $(131 \pm 7) /[5.3]$ & $(129 \pm 8) /[6.2]$ & $3 \mathrm{~mL} \mathrm{HNO}_{3}+3 \mathrm{~mL} \mathrm{HF}+2 \mathrm{~mL} \mathrm{H}_{2} \mathrm{SO}_{4}$ \\
\hline 3 & $(118 \pm 3) /[2.5]$ & $(118 \pm 3) /[2.5]$ & $(117 \pm 3) /[2.6]$ & $3 \mathrm{~mL} \mathrm{HF}+2 \mathrm{~mL} \mathrm{H}_{2} \mathrm{SO}_{4}+1 \mathrm{~mL} \mathrm{H}_{2} \mathrm{O}_{2}$ \\
\hline 4 & $(139 \pm 4) /[2.9]$ & $(139 \pm 4) /[2.9]$ & $(137 \pm 4) /[2.9]$ & $3 \mathrm{~mL} \mathrm{HF}+2 \mathrm{~mL} \mathrm{H}_{2} \mathrm{SO}_{4}+3 \mathrm{~mL} \mathrm{HCl}$ \\
\hline 5 & $(132 \pm 9) /[6.8]$ & $(133 \pm 9) /[6.8]$ & $(130 \pm 10) /[7.7]$ & $2 \mathrm{~mL} \mathrm{HNO}_{3}+2 \mathrm{~mL} \mathrm{HClO}+1 \mathrm{~mL} \mathrm{HF}$ \\
\hline 6 & $(126 \pm 15) /[11.9]$ & $(126 \pm 15) /[11.9]$ & $(123 \pm 15) /[12.2]$ & $2 \mathrm{~mL} \mathrm{HNO}_{3}+1 \mathrm{~mL} \mathrm{HBF}_{4}+2 \mathrm{~mL} \mathrm{HClO}_{4}$ \\
\hline
\end{tabular}

Certified total mercury concentration $(132 \pm 3){\mu g^{-1}}^{-1}$

It was found that addition of $\mathrm{H}_{2} \mathrm{O}_{2}$ or $\mathrm{HCl}$ or $\mathrm{HClO}_{4}$ to $\mathrm{HNO}_{3}$ did not improve the performance of digestion. Therefore, after evaluation of obtained results, finally, the concentrated solution of $\mathrm{HNO}_{3}$ was selected for the digestion of samples with organic matrix, M_3, M_4, and M_5.

\section{Optimization of digestion conditions for "MODAS" samples}

The optimized digestion conditions for the inorganic and organic-like matrices were applied for the decomposition of "MODAS" samples (Table 4). The determination of mercury concentration was performed either with the use of the calibration curve (CV AAS or ICP MS) or with the standard addition (ICP MS). External calibration standards of mercury were at the level of 1, 5, and $10 \mu \mathrm{g} \mathrm{L}^{-1}$ and were prepared gravimetrically in $3 \%$ $\mathrm{HCl}$ (for $\mathrm{CV} \mathrm{AAS}$ ) or in $2 \% \mathrm{HNO}_{3}$ (for ICP MS).

In the case of ICP MS measurements, rhodium was used as an internal standard. The intensities of three isotopes ${ }^{200} \mathrm{Hg}$, ${ }^{201} \mathrm{Hg}$, and ${ }^{202} \mathrm{Hg}$ were monitored in "MODAS" samples without and with the addition of gold solution. By using the most abundant isotope ${ }^{202} \mathrm{Hg}$, the regression equation was $y=3090.9 x$ with the correlation coefficient $R^{2}=0.9998$; precision was less than $2.5 \%$ for the investigation concentrations range; the limit of quantification and detection were $0.48 \mu \mathrm{g}$ $\mathrm{kg}^{-1}$ and $0.18 \mu \mathrm{g} \mathrm{kg}^{-1}$, respectively. In order to evaluate any possible matrix effects, the standard addition was also applied.
To each sample, a set of three known amounts of mercury standards was added gravimetrically and proportionally to the mercury concentration in sample. The precision was less than $2 \%$ for the investigated concentrations range. The results of mercury content in all samples were identical (within their uncertainty) for all monitored isotopes. Thus, in Table 7, only the results for the most abundant isotope ${ }^{202} \mathrm{Hg}$ were listed.

The measurements performed by ICP MS were conducted first with the use of external calibration, when rhodium was added as an internal standard. Next, the standard addition ICP MS was applied. The results obtained with ICP MS by the standard addition method were significantly higher, compared to those obtained with the use of the external calibration (except M_4, results were in agreement within uncertainty). Therefore, it was decided to add gold solution as preservative agent during the digestion step. This work focused on the development and validation of methodologies for the accurate determination of mercury in environmental samples and its further application for the preparation and certification of new reference materials. Two certified reference materials ERM-CC580 (inorganic matrix) and ERM-CE464 (organic matrix) were used for the evaluation of digestion conditions assuring the quantitative recovery of mercury. These conditions were then used for the digestion of new candidates for the environmental reference materials (RMs): bottom sediment (M_2 BotSed), herring tissue (M_3 HerTis), cormorant tissue (M_4 CormTis), and

Table 6 Mercury concentration in ERM-CE464 certified reference material. Results expressed in microgram per gram (the extended uncertainty $\left.(k=2), \mu \mathrm{g} \mathrm{g}^{-1} / \%\right)$. Digestion conditions as in program II

\begin{tabular}{|c|c|c|c|c|}
\hline No. & $\mathrm{C}_{\mathrm{Hg}}\left({ }^{200} \mathrm{Hg} \pm \mathrm{Uc}\right) / \mathrm{Uc}[\%]$ & $\mathrm{C}_{\mathrm{Hg}}\left({ }^{201} \mathrm{Hg} \pm \mathrm{Uc}\right) / \mathrm{Uc}[\%]$ & $\mathrm{C}_{\mathrm{Hg}}\left({ }^{202} \mathrm{Hg} \pm \mathrm{Uc}\right) / \mathrm{Uc}[\%]$ & Composition of digestion mixture \\
\hline 1 & $(5.60 \pm 0.09) /[1.6]$ & $(5.60 \pm 0.09) /[1.6]$ & $(5.57 \pm 0.08) /[1.4]$ & $1 \mathrm{~mL} \mathrm{H}_{2} \mathrm{O}_{2}+4 \mathrm{~mL} \mathrm{HNO}_{3}$ \\
\hline 2 & $(4.90 \pm 0.08) /[1.6]$ & $(4.92 \pm 0.07) /[1.4]$ & $(4.86 \pm 0.06) /[1.2]$ & $1 \mathrm{~mL} \mathrm{H}_{2} \mathrm{O}_{2}+3 \mathrm{~mL} \mathrm{HNO}_{3}+3 \mathrm{~mL} \mathrm{HCl}$ \\
\hline 3 & $(5.81 \pm 0.08) /[1.4]$ & $(5.83 \pm 0.08) /[1.4]$ & $(5.77 \pm 0.06) /[1.0]$ & $1 \mathrm{~mL} \mathrm{HNO}_{3}+3 \mathrm{~mL} \mathrm{HCl}$ \\
\hline 4 & $(5.77 \pm 0.14) /[2.4]$ & $(5.80 \pm 0.12) /[2.0]$ & $(5.73 \pm 0.12) /[2.1]$ & $3 \mathrm{~mL} \mathrm{HNO}_{3}+1 \mathrm{~mL} \mathrm{HClO} 4$ \\
\hline 5 & $(5.23 \pm 0.14) /[2.7]$ & $(5.22 \pm 0.12) /[2.3]$ & $(5.18 \pm 0.12) /[2.3)]$ & $5 \mathrm{~mL} \mathrm{HNO}_{3}$ \\
\hline
\end{tabular}

Certified total mercury concentration $(5.24 \pm 0.10) \mu \mathrm{g} \mathrm{g}^{-1}$ 
Table 7 Mercury concentration in "MODAS" materials with the use of ICP MS and CVAAS. Results expressed in nanogram per gram (the extended uncertainty $\left.(k=2), \operatorname{ng~g}^{-1} / \%\right)$

\begin{tabular}{cllll}
\hline Method & $\begin{array}{l}\text { ICP MS calibration curve } \\
(\text { no addition of } \mathrm{Au})\end{array}$ & $\begin{array}{l}\text { ICP MS calibration curve } \\
\text { (with addition of Au) }\end{array}$ & ICP MS standard addition & $\begin{array}{l}\text { CV AAS calibration } \\
\text { curve peak area mode }\end{array}$ \\
\hline Material & $\mathrm{C}_{\mathrm{Hg}}\left({ }^{202} \mathrm{Hg} \pm \mathrm{Uc}\right) / \mathrm{Uc}[\%]$ & $\mathrm{C}_{\mathrm{Hg}}\left({ }^{202} \mathrm{Hg} \pm \mathrm{Uc}\right) / \mathrm{Uc}[\%]$ & $\left(\mathrm{C}_{\mathrm{Hg}} \pm \mathrm{Uc}\right) / \mathrm{Uc}[\%]$ & $\left(\mathrm{C}_{\mathrm{Hg}} \pm \mathrm{Uc}\right) / \mathrm{Uc}[\%]$ \\
M_2 BotSed & $(399 \pm 15) /[3.8]$ & $(863 \pm 47) /[4.3]$ & $(883 \pm 25) /[2.9]$ & $(951 \pm 67) /[7.1]$ \\
M_3 HerTis & $(116 \pm 6) /[5.5]$ & $(239 \pm 16) /[5.6]$ & $(247 \pm 8) /[3.5]$ & $(245 \pm 21) /[8.7]$ \\
M_4 CormTis & $(2108 \pm 89) /[4.2]$ & $(2080 \pm 82) /[4.0]$ & $(2284 \pm 130) /[5.7]$ & $(2238 \pm 81) /[3.6]$ \\
M_5 CodTis & $(241 \pm 17) /[6.9]$ & $(294 \pm 21) /[8.6]$ & $(314 \pm 16) /[5.0]$ & $(297 \pm 14) /[4.6]$ \\
\hline
\end{tabular}

codfish muscle (M_5 CodTis). Cold vapor atomic absorption spectrometry (CV AAS) and inductively coupled plasma mass spectrometry (ICP MS) were used for the measurement of mercury concentration in all RMs. In order to validate and assure the accuracy of results, isotope dilution mass spectrometry (IDMS) was applied as a primary method of measurement, assuring the traceability of obtained values to the SI units: the mole, the kilogram, and the second. Results obtained by IDMS using $n\left({ }^{200} \mathrm{Hg}\right) / n\left({ }^{202} \mathrm{Hg}\right)$ ratio, with estimated combined uncertainty, were as follows: $(916 \pm 41) /[4.5 \%] \mathrm{ng} \mathrm{g}^{-1}$ (M_2 BotSed), $(236 \pm 14) /[5.9 \%] \mathrm{ng} \mathrm{g}^{-1}$ (M_3 HerTis), $(2252 \pm 54) /[2.4 \%] \mathrm{ng} \mathrm{g}^{-1}$ (M_4 CormTis), and $(303 \pm 15) /[4.9 \%] \mathrm{ng} \mathrm{g}^{-1}$ (M_CodTis), respectively. Different types of detection techniques and quantification (external calibration, standard addition, isotope dilution) were applied in order to improve the quality of the analytical results. The good agreement (within less than $2.5 \%$ ) between obtained results and those derived from the Inter-laboratory Comparison, executed by the Institute of Nuclear Chemistry and Technology (Warsaw, Poland) on the same sample matrices, was achieved. It has been known that gold will amalgamate mercury, thus preventing other side reactions as well as overcoming the problem of memory effect (Allibone et al. 1999). For this purpose, the 100-fold excess of gold standard solution (proportional to the mercury content in "MODAS" samples) was gravimetrically added to each sample and procedural blank, before the digestion step, and then digestion procedure was applied. The gold standard solution was also added to the mercury standard solutions: 1,5 , and $10 \mu \mathrm{g} \mathrm{L}^{-1}$ prepared gravimetrically, as to reach 100,500 , and $1000 \mu \mathrm{g} \mathrm{L} \mathrm{L}^{-1}$ of gold in the standard solution, respectively. With this approach, the results of mercury concentrations achieved by the calibration curve ICP MS were in agreement within uncertainty with results obtained by standard addition method.

CV AAS was used in order to assure the accuracy of the results of mercury concentrations obtained by ICP MS. The regression equation was $y=0.0094 x$ with the correlation coefficient $R^{2}=0.9996$; precision was less than $3 \%$ for the investigation concentrations range; limits of quantification and detection of $0.54 \mu \mathrm{g} \mathrm{kg}^{-1}$ and $0.25 \mu \mathrm{g} \mathrm{kg}^{-1}$ were received, respectively. The measurement conditions of CV AAS, as listed in Table 3, were validated by measuring the concentration of mercury in the ERM-CE464. Calculated concentration of mercury in the ERM-CE464 was in good agreement with the certified value. The results obtained for "MODAS" samples (Table 7) were found to be in a good agreement within their uncertainty with the results, when the calibration curve with gold standard solution was added and the standard addition ICP MS were applied.

\section{Isotope dilution mass spectrometry as a primary method of measurement for mercury determination}

In order to evaluate the accuracy of the results presented in Table 7, IDMS was applied as a primary method of measurement. The optimal amount of isotopically enriched standard was calculated to alter natural isotopic composition of mercury (from 0.77 till around 0.2 ) in the samples. The ERMAE640 isotopically enriched standard $(95.7 \%$ abundance for ${ }^{202} \mathrm{Hg}$ ) was used for this purpose (Certificate of ERMAE640 2016). Established amounts of isotopically enriched
Table 8 Mercury concentration in MODAS reference materials: (i) calculated from $n\left({ }^{200} \mathrm{Hg}\right) /$ $n\left({ }^{202} \mathrm{Hg}\right)$ and $n\left({ }^{201} \mathrm{Hg}\right) / n\left({ }^{202} \mathrm{Hg}\right)$ ratios; (ii) from Inter-laboratory Comparison (ILC). Results are expressed in nanogram per gram (the extended uncertainty $(k=2)$, $\left.\operatorname{ng~g}^{-1} / \%\right)$

\begin{tabular}{llll}
\hline Material & \multicolumn{1}{l}{ IDMS } & & $\mathrm{C}_{\mathrm{Hg}} \pm \mathrm{Uc}(k=2) \operatorname{ILC}[\%]$ \\
\cline { 2 - 3 } & $n\left({ }^{200} \mathrm{Hg}\right) / n\left({ }^{202} \mathrm{Hg}\right)[\%]$ & $n\left({ }^{201} \mathrm{Hg} / n\left({ }^{202} \mathrm{Hg}\right)[\%]\right.$ & \\
\hline MODAS 2 & $(916 \pm 41) /[4.5]$ & $(899 \pm 40) /[4.4]$ & $(884 \pm 53) /[6.0]$ \\
MODAS 3 & $(236 \pm 14) /[5.9]$ & $(237 \pm 14) /[5.9]$ & $(227 \pm 21) /[9.2]$ \\
MODAS 4 & $(2232 \pm 54) /[2.4]$ & $(2234 \pm 54) /[2.4]$ & $(2200 \pm 140) /[6.4]$ \\
MODAS 5 & $(303 \pm 15) /[4.9]$ & $(301 \pm 15) /[4.9]$ & $(310 \pm 22) /[7.1]$
\end{tabular}


Table 9 Main sources of uncertainty of mercury concentration in "MODAS" materials by means of IDMS

\begin{tabular}{ccccc}
\hline Element of budget & $\begin{array}{l}\text { MODAS 2 } \\
(\%)\end{array}$ & $\begin{array}{l}\text { MODAS 3 } \\
(\%)\end{array}$ & $\begin{array}{l}\text { MODAS 4 } \\
(\%)\end{array}$ & $\begin{array}{l}\text { MODAS 5 } \\
(\%)\end{array}$ \\
\hline & 88.0 & 91.8 & 92.3 & 78.7 \\
Dead time & 2.3 & 1.7 & 2.5 & 5.8 \\
Concentration of ERM AE640 standard & 2.5 & 1.7 & 1.6 & 4.4 \\
\% abundance of ${ }^{198} \mathrm{Hg}$ in the standard & 1.8 & 0.5 & 0.4 & 1.3 \\
\% abundance of ${ }^{199} \mathrm{Hg}$ in the standard & 0.4 & 0.6 & 0.5 & 1.5 \\
\% abundance of ${ }^{200} \mathrm{Hg}$ in the standard & 1.2 & 0.4 & 0.4 & 1.1 \\
\% abundance of ${ }^{202} \mathrm{Hg}$ in the standard & 1.2 & 0.4 & 0.4 & 1.0 \\
\% abundance of ${ }^{204} \mathrm{Hg}$ in the standard & 0.6 & 0.3 & 0.3 & 0.7 \\
Determination of isotopic ratio in mixture 1 & 0.2 & 0.4 & 0.4 & 0.8 \\
Determination of isotopic ratio in mixture 2 & 0.6 & 0.8 & 0.0 & 1.6 \\
Determination of isotopic ratio in mixture 3 & 0.4 & 0.4 & 0.2 & 0.4 \\
Water content & 0.8 & 0.6 & 0.1 & 0.3 \\
\hline
\end{tabular}

standard (0.45 g, $0.16 \mathrm{~g}, 1.7 \mathrm{~g}$, and $0.26 \mathrm{~g})$ were added gravimetrically to the "MODAS" samples (to M_2, M_3, M_4, and M 5, respectively). Two isotopic ratios were calculated: $n\left({ }^{200} \mathrm{Hg}\right) / n\left({ }^{202} \mathrm{Hg}\right)$ and $n\left({ }^{201} \mathrm{Hg}\right) / n\left({ }^{202} \mathrm{Hg}\right)$ by monitoring most abundant isotopes of mercury by ICP MS. Special attention was paid to assure that the isotopic equilibrium was achieved, after mixing of the sample and spike during digestion. In the case of M_2, results were corrected mathematically due to tungsten presence in the sample, which formed ${ }^{184} \mathrm{~W}^{16} \mathrm{O}^{+}$ and ${ }^{186} \mathrm{~W}^{16} \mathrm{O}^{+}$ions. In the other three materials, the content of tungsten was sufficiently low; thus, interferences were not observed. It can be seen in Table 8 that mercury concentrations calculated from two different isotopic ratios with the use of basic IMDS equation (Heumann 2004; Vogl and Pritzkow 2010) were in very good agreement within uncertainty values. It should be stressed that mercury concentrations in "MODAS" reference materials reported by the organizer (Institute of Nuclear Chemistry and Technology (Warsaw, Poland)) of Inter-laboratory Comparison, ILC (Table 8), are consistent with mercury concentrations obtained in this study with the use of different analytical techniques and calibration strategies: the calibration curve and the standard addition ICP MS, CV AAS technique, and a direct IDMS.

The extended uncertainty of measurement results was estimated for entire IDMS procedure. All factors influencing the final results, as well as isotopic equilibrium, were systematically investigated. This included the procedural blank, the moisture content in "MODAS" samples, and all factors affecting the blend ratio measurements (instrumental background, spectral interferences, dead time, and mass discrimination effects as well as the repeatability of measured isotopic ratios). For the evaluation of uncertainties of measurement values, the GUM Workbench 2.4 (Metrodata GmbH 2016) software was used. Budget of uncertainty for IDMS measurements is presented in Table 9. It can be seen that concentration of mercury in blank was a dominant source of uncertainty in all studied "MODAS" materials, what means that applied measurement conditions confirmed the metrological quality of obtained results.

\section{Conclusions}

In this work, analytical methodologies for the accurate determination of mercury in environmental samples of inorganic or organic origins were developed. Subsequently, developed conditions were applied for the preparation of new reference materials with the proposed certified values for mercury. In order to assure the accuracy of the results, two certified reference materials (ERM-CC580 and ERM-CC464) were used. Recoveries close to $100 \%$ of the certified values, within uncertainties, were achieved with the use of optimized digestion procedures for inorganic and organic matrix, respectively. The same digestion conditions were used for new reference materials called "MODAS" CRMs. The determination of mercury was then performed with the use of CV AAS, ICP MS (with external calibration or standard addition strategy), and finally validated by IDMS as a primary method of measurement. The mercury concentrations obtained by means of ICP MS (by external calibration in the presence of gold solution) and $\mathrm{CV}$ AAS were in good agreement within their uncertainties. On the base of those results, the optimal amount of isotopically enriched standard was calculated for alteration of natural mercury isotopic ratios in "MODAS" samples and IDMS for mercury determination was applied. Application of IDMS enabled traceability of obtained results to SI units and assured the accuracy of measurements. Water content in all materials used in this study was established by dry mass correction. The determined concentrations of mercury in "MODAS" reference materials were cross-validated with records from Interlaboratory Comparison. The difference between obtained results in this study and those derived from ILC on the same sample matrices was less than $2.5 \%$ and further validated the 
developed methodologies for the accurate determination of mercury in environmental samples. It should be highlighted that the obtained results by IDMS for mercury concentrations were used later as a contribution of the Biological and Chemical Research Centre in the frame of certification process of "MODAS" reference materials organized by the Institute of Nuclear Chemistry and Technology.

The methodology developed within this study was used for certification of mercury concentration in selected candidates for environmental reference materials. Despite the measurement technique, the limit of detection was found to be around $0.2 \mu \mathrm{g} \mathrm{kg}^{-1}$. The lowest extended uncertainty of results, below $5.9 \%$, was obtained when the standard addition ICP MS or IDMS was used which was lower than the values provided by the organizer of respective ILC. Thus, the developed protocols could be recommended as a generally valid for the certification of reference materials of environmental origin.

Acknowledgment The work was founded by the National Centre for Research and Development within a project "Development and attestation of new types of reference materials necessary to achieve European accreditation by the Polish laboratories for industrial analytics""INNOTECH-MODAS" [http://www.pg.gda.pl/chem/modas/].

The study was carried out at the Biological and Chemical Research Centre, University of Warsaw, established within the project co-financed by the European Union from the European Regional Development Fund under the Operational Programme Innovative Economy, 2007-2013.

Authors acknowledge the Institute of Nuclear Chemistry and Technology, Warsaw, Poland, (H. Polkowska-Motrenko, R. Dybczyński, Z. Samczyński) for providing data from Inter-laboratory Comparison.

Open Access This article is distributed under the terms of the Creative Commons Attribution 4.0 International License (http:// creativecommons.org/licenses/by/4.0/), which permits unrestricted use, distribution, and reproduction in any medium, provided you give appropriate credit to the original author(s) and the source, provide a link to the Creative Commons license, and indicate if changes were made.

\section{References}

Aurelio M, Arruda Z (ed) (2007) Trends in samples preparation, Nova Science Publishers Inc., pp. 304 ISBN: 978-1-60021-118-8

Allibone J, Fatemian E, Walker PJ (1999) Determination of mercury in potable water by ICP-MS using gold as a stabilising agent. J Anal At Spectrom 14:235-239

Arslan Z, Ertas N, Tyson JF, Uden PC, Denoyer ER (2000) Determination of trace elements in marine plankton by inductively coupled plasma mass spectrometry (ICP-MS). Fresenius J Anal Chem 366:273-282

Berglund M, Wieser ME (2011) Isotopic compositions of the elements 2009 (IUPAC technical report). Pure Appl Chem 83:397-410

Bruhn CG, Rodríguez AA, Barrios C, Jaramillo VH, Becerra J, González U, Gras NT, Reyes O, Salud S (1994) Determination of total mercury in scalp hair of humans by gold amalgamation cold vapour atomic absorption spectrometry. J Anal At Spectrom 9:535-541

Bulska E (2009) Quality assurance and quality control of analytical results. In: Namiesnik J, Szefer P (ed) Analytical measurements in aquatic environments, CRC Press, Taylor \& Francis Group, pp 389-397 ISBN 978-1-4200-8268-5
Cattani I, Spalla S, Beone GM, Del Rea AAM, Boccelli R, Trevisan M (2008) Characterization of mercury species in soils by HPLC-ICPMS and measurement of fraction removed by diffusive gradient in thin films. Talanta 74:1520-1526

Certificate of ERM-AE640 Isotopically enriched standard, available online: https://ec.europa.eu/jrc/sites/default/files/rm/ERM-AE640 cert.pdf Accessed 12 February 2016

Chen W, Wee P, Brindle ID (2000) Elimination of the memory effects of gold, mercury and silver in inductively coupled plasma atomic emission spectroscopy. J Anal At Spectrom 15:409-413

da Silva MJ, Paim APS, Pimentel MF, Cervera ML, de la Guardia M (2010) Determination of mercury in rice by cold vapor atomic fluorescence spectrometry after microwave-assisted digestion. Anal Chim Acta 667:43-48

Falciani R, Novaro E, Marchesini M, Gucciardi M (2000) Multi-element analysis of soil and sediment by ICP-MS after a microwave assisted digestion method. J Anal At Spectrom 15:561-565

Falter R, Ilgen G (1997) Determination of trace amounts of methylmercury in sediment and biological tissue by using water vapor distillation in combination with RP C18 preconcentration and HPLC-HPF/ HHPN-ICP-MS. Fresenius J Anal Chem 358:401-406

Harada M, Nakachib S, Cheuc T, Hamadac H, Onod Y, Tsudae T, Yanagidaf K, Kizaki T, Ohnog H (1999) Monitoring of mercury pollution in Tanzania: relation between head hair mercury and health. Sci Total Environ 227:249-256

Harrington CF, Merson SA, D' Silva TM (2004) Method to reduce the memory effect of mercury in the analysis of fish tissue using inductively coupled plasma mass spectrometry. Anal Chim Acta 505: 247-254

Heumann KG (2004) Isotope-dilution ICP-MS for trace element determination and speciation: from a reference method to a routine method? Anal Bioanal Chem 378:318-329

Hoenig M (2001) Preparation steps in environmental trace element analysis - facts and traps. Talanta 54:1021-1038

Kenduzler E, Ates M, Arslan Z, McHenry M, Tchounwou PB (2012) Determination of mercury in fish otoliths by cold vapor generation inductively coupled plasma mass spectrometry (CVG-ICP-MS). Talanta 93:404-410

Knight R, Haswell SJ, Lindow SW, Batty J (1999) Determination of mercury in hair by coupled CVAA-ICP-MS. J Anal At Spectrom 14:127-129

Krata A, Kopyść E, Pyrzyńska K, Bulska E (2002) Analytical performance of solid sorbents for mercury speciation. Chem Anal 47:429-437

Krata A, Pyrzyńska K, Bulska E (2003) Use of solid-phase extraction to eliminate interferences in the determination of mercury by flowinjection CV AAS. Anal Bioanal Chem 377:735-739

Leermakers M, Baeyens W, Quevauviller P, Horvat M (2005) Mercury in environmental samples: speciation, artifacts and validation. Trends Anal Chem 24:383-393

Li X, Wang Z (2007) Determination of mercury by intermittent flow electrochemical cold vapor generation coupled to atomic fluorescence spectrometry. Anal Chim Acta 588:179-183

Li Y, Chen C, Li B, Sun J, Wang J, Gao Y, Zhao Y, Chai Z (2006) Elimination efficiency of different reagents for the memory effect of mercury using ICP-MS. J Anal At Spectrom 21:94-96

Lubick N (2009) Funding struggle for mercury monitoring. Nature 459: $620-621$

McShane WJ, Pappas RS, Wilson-McElprang V, Paschal D (2008) A rugged and transferable method for determining blood cadmium, mercury, and lead with inductively coupled plasma-mass spectrometry. Spectrochim Acta Part B 63:638-644

Metrodata GmbH GUM Workbench 2.4 (The Software Tool for the Expression of Uncertainty in Measurement) http://www.metrodata. de/index_en.html Accessed 12 February 2016 
Nelms SM, Quetel CR, Prohaska T, Taylor PDP (2001) Evaluation of detector dead time calculation models. J Anal At Spectrom $16: 333-338$

Perring L, Alonso MI, Andrey D, Bourqui B, Zbinden P (2001) An evaluation of analytical techniques for determination of lead, cadmium, chromium, and mercury in food-packaging materials. Fresenius J Anal Chem 370:76-81

Quevauviller P, Maier EA, Griepink B, Fortunati U, Vercoutere K, Muntau H (1996) Certified reference materials of soils and sewage sludges for the quality control of trace element environmental monitoring. Trends Anal Chem 15:504-513

Quinn TJ (1997) Primary methods of measurement and primary standards. Metrologia 34:61-65

Shah AQ, Kazi TG, Baig JA, Afridi HI, Kandhro GA, Arain MB, Kolachi NF, Wadhwa SK (2010) Total mercury determination in different tissues of broiler chicken by using cloud point extraction and cold vapor atomic absorption spectrometry. Food Chem Toxicol 48:65-69

Shuqin C, Hangting C, Xianjin Z (1999) Determination of mercury in biological samples using organic compounds as matrix modifiers by inductively coupled plasma mass spectrometry. J Anal At Spectrom 14:1183-1186
Smith RG (1993) Determination of mercury in environmental samples by isotope dilution ICPMS. Anal Chem 65:2485-2488

Soares dos Santos J, de la Guárdia M, Pastor A, Pires dos Santos ML (2009) Determination of organic and inorganic mercury species in water and sediment samples by HPLC on-line coupled with ICPMS. Talanta 80:207-211

Taylor P, Kistronyhardt H, de Bievre P (2001) The definition of primary method of measurement (PMM) of the "highest metrological quality": a challenge in understanding and communication. Accred Qual Assur 6:103-106

Torres DP, Borges DLG, Frescura VLA, Curtius AJ (2009) A simple and fast approach for the determination of inorganic and total mercury in aqueous slurries of biological samples using cold vapor atomic absorption spectrometry and in situ oxidation. J Anal At Spectrom 24: $1118-1122$

Vogl J, Pritzkow W (2010) Isotope dilution mass spectrometry — a primary method of measurement and its role for RM certification. MAPAN-JMSI 25:135-164

Wu XH, Sun DH, Zhuang ZX, Wang XR, Gong HF, Hong JX, Lee FSC (2002) Analysis and leaching characteristics of mercury and arsenic in Chinese medicinal material. Anal Chim Acta 453:311-323 